Saudi Journal of Oral and Dental Research

Abbreviated Key Title: Saudi J Oral Dent Res ISSN 2518-1300 (Print) |ISSN 2518-1297 (Online)

Scholars Middle East Publishers, Dubai, United Arab Emirates

Journal homepage: http://scholarsmepub.com/sjodr/

Case Report

\title{
A Rare Presentation of Mucocele in Pediatric Oral Cavity: A Case Report
}

Dr. Hirdepal Singh Brar, $\mathrm{MDS}^{1 *}$, Dr. Ravi Narula, $\mathrm{MDS}^{2}$, Dr. Rishabh Bhanot ${ }^{3}$, Dr. Amarjot Brar, $\mathrm{MDS}^{4}$, Dr Noufila $\mathrm{Mol}^{5}$, Dr. Arjun Sreenivas ${ }^{6}$

${ }^{1}$ Consultant Oral and Maxillofacial Surgeon, Faridkot, Punjab India

${ }^{2}$ Professor and Head, Department of OMFS, Guru Nanak Dev Dental College and Research Institute, Sunam, Punjab India

${ }^{3}$ Consultant Oral and Maxillofacial surgeon, SRCJC Hospital, Ludhiana Punjab India

${ }^{4}$ Consultant Orthodontist, Faridkot Punjab India

53 rd year post graduate, Dept of pedodontic and preventive Dentistry, PMS College of dental science and research, Trivandrum, Kerala India

${ }^{6}$ Senior Lecturer, Dept of pedodontic and preventive Dentistry, PMS College of dental science and research, Trivandrum, Kerala India

DOI: $10.36348 /$ sjodr.2019.v04i11.001 | Received: 27.10.2019| Accepted: 03.11.2019| Published: 15.11 .2019

*Corresponding author: Dr. Hirdepal Singh Brar, MDS

\section{Abstract}

Mucoceles are common in oral cavity, but rare in pediatric patients. Diagnosis and management of mucocele is challenging. Surgical excision is an appropriate treatment modality with least recurrence and good prognosis. This is a case report of 12 year old with mucocele on the left side of the ventral surface of the tongue.

Keywords: pediatric, ventral surface, mucocele, common.

Copyright @ 2019: This is an open-access article distributed under the terms of the Creative Commons Attribution license which permits unrestricted use, distribution, and reproduction in any medium for non-commercial use (NonCommercial, or CC-BY-NC) provided the original author and source are credited.

\section{INTRODUCTION}

Term Mucocele define the subepithelial accumulation of mucous secreted from salivary glands and their ducts in the mucosa of oral cavity [1]. It is derived from a Latin word, mucus and coele means cavity [2]. Mucocele is seventeenth most common salivary gland lesions seen in the oral cavity [3]. Mucocele is seen frequently on lower labial mucosa, buccal mucosa, tongue, retromolar area, upper lip, hard palate and floor of mouth $[4,5]$.

\section{CASE REPORT}

A 12 yr old male child presented to the department with chief complaint of swelling on the lower side of the tongue for past 3 months. History dated back to 3 months when patient had a trauma while playing. Patient noticed the swelling which gradually increased to the present size. The swelling was painless and there was no discharge. There was no relevant past medical \& dental history. On examination, the face of the patient was bilaterally symmetrical with no remarkable findings.

On intraoral inspection, a well-defined solitary, oval, painless, non-ulcerated swelling was seen on the left ventral surface of the tongue, with a translucent hue measuring $4 \times 3 \mathrm{~cm}$ (approx.) in size( fig I). On palpation the swelling was soft to firm in consistency, non- tender, fluctuant, non-reducible, nonpulsatile with a smooth surface \& no increase in the temperature.

A provisional diagnosis of mucocele on the ventral surface of the tongue with the differential diagnosis of soft tissue abscess, lymphangioma, fibroma and hemangioma was made. Surgical excision the complete lesion was done and was sent for histopathological examination. The closure was done using purse- string suturing technique using 4-0 prolene suture (fig. II). H\& E stained sections revealed the mucocele of extravasation type (fig. III). 


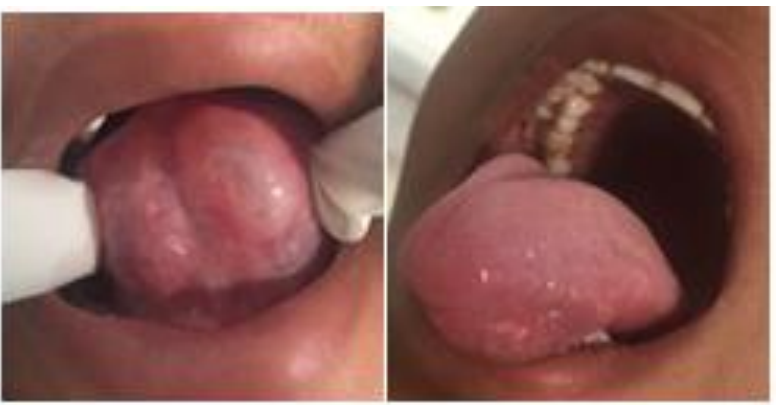

Fig-I: Oval shaped swelling $4 \times 3 \mathrm{~cm}$ on ventral surface of tongue
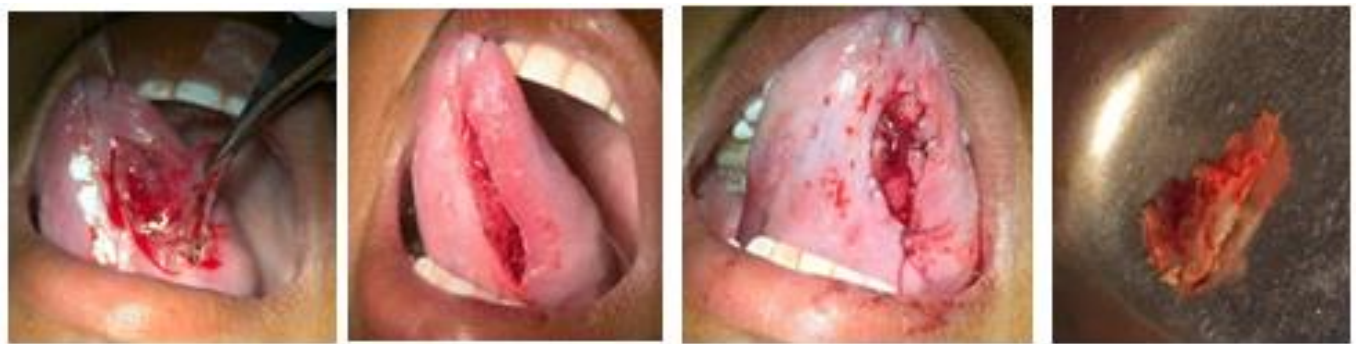

Fig-II: Surgical procedure and the specimen

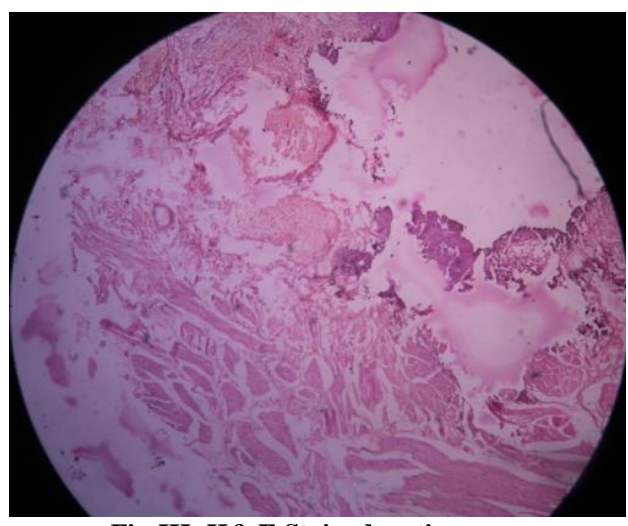

Fig-III: H\& E Stained section

\section{DISCUSSION}

Mucocele is the second most common benign soft tissue tumor occurring frequently in the second decade of life and rarely occurring in infants under 1 year of age [6].

Clinically there are two types, extravasation and retention type. Extravasation type is due to the leakage of fluid from the broken salivary gland ducts and acini into the surrounding soft tissues. Retention type is due to blockage of salivary gland duct and acini. When located in floor of the mouth it appears as the underbelly of a frog, so called as ranula. Other two clinical variants are: Superficial mucocele that is located directly under the mucosa and classic variant located in the upper submucosa [9]. Mucocele can be traumatic or non- traumatic in origin [6].

The diagnosis of Mucocele is based principally on the clinical examination. It usually presents as a bluish, soft, transparent cystic swelling which frequently resolves spontaneously. Fine needle aspiration cytology could be done, that may show mucus with inflammatory cells and may aid in the diagnosis [6].

The lesion can be excised completely or treated with marsupilization. The cryosurgery is an effective method of treatment. Steroids also play an important role in the treatment of mucocele, a single intra lesional steroid injection, preceded by aspiration of the cyst fluid can be done. It causes the pseudocyst wall to collapse and triggers a severe inflammaroty reaction of the wall that results in marked fibrosis $[4,6]$.

\section{CONCLUSION}

Mucocele is the most common benign self limiting condition of the oral mucosa occurring on lower lip mostly due to trauma or lip biting habit. This case report presents a rare presentation of the mucocele on the ventral surface of the tongue. Surgical excision with dissection of the surrounding and contributing minor salivary glands was performed. Management of mucocele becomes challenging because of the high possibility of recurrence. Purse string sutures were 
placed in our case and it prevented the recurrence of the mucocele in the follow up of 3 months.

\section{Ethical Approval} required

For this type of study, formal consent is not

\section{REFERENCES}

1. Pedron, I. G., Galletta, V. C., Azevedo, L. H., \& Corrêa, L. (2010). Treatment of mucocele of the lower lip with diode laser in pediatric patients: presentation of 2 clinical cases. Pediatric dentistry, 32(7), 539-541.

2. Yagüe García, J., España Tost, A. J., Berini Aytés, L., \& Gay Escoda, C. (2009). Treatment of oral mucocele-scalpel versus C02 laser. Medicina Oral,
Patología Oral y Cirugia Bucal, 2009, vol. 14, num. 9, p. 469-474.

3. Flaitz, C.M., Hicks J.M.(2012). Mucocele and ranula. eMedicine.

4. Senthilkumar, Mahaboob, M.N. (2012). Mucocele: An unusual presentation of the minor salivary gland lesion. J Pharm Bioallied Sci, 4(2): S180S182.

5. Daniels, J., \& Al Bakri, I. M. (2005). Mucocele of lingual glands of Blandin and Nuhn: A report of 5 cases. Saudi Dent J, 17(3), 154-161.

6. Marathe, S., Hebbale, M., Nisa, S. U., \& Harchandani, N. (2014). Oral Mucocele: Presentation at a Rare Site with Review. Int J Adv Health Sci, 1(4), 14-18. 